\author{
Location, Location, Location! \\ A Classroom Demonstration of the Hotelling Model
}

\author{
Lisa R. Anderson \\ College of William and Mary \\ Beth A. Freeborn \\ College of William and Mary \\ Jessica Holmes \\ Middlebury College \\ Mark Jeffreys \\ Utah Valley State College \\ Dan Lass \\ University of Massachusetts \\ Jack Soper \\ John Carroll University
}

College of William and Mary

Department of Economics

Working Paper Number 44

Original Version: September 2006

Current Version: July 2008

We would like to thank participants at the NSF Workshop on Classroom Experiments in Montreal as well as participants at the 2005 ESA North American Meeting for their feedback on earlier drafts of this paper. We are especially grateful to Jeffrey Carpenter, Rachel Croson, Sofronis Clerides, Caitlin Knowles Myers, David Reiley, and Thierry Warin for helpful comments and suggestions. We gratefully acknowledge financial support from the National Science Foundation (SBR-0094800). 
COLLEGE OF WILLIAM AND MARY

DEPARTMENT OF ECONOMICS

WORKING PAPER \# 44

Original: September 2006

Current: July 2008

Location, Location, Location! A Classroom Demonstration of the Hotelling Model

\begin{abstract}
This paper outlines a classroom experiment that complements the standard theoretical discussion of Hotelling's (1929) spatial competition model. The exercise provides students with a deeper understanding of the intuition behind competitive clustering, resolving the Bertrand paradox, and product positioning. Students act as street vendors operating within a "linear city." Each student chooses a location, taking into account the locations of competitors and the transportation costs of customers. Other treatments include choosing price given location and a two-stage model of location and price. The experiment can be implemented in any size class, with very little preparation. It is well-suited for courses in microeconomics, industrial organization, game theory, experimental economics, and public choice economics, and also can be incorporated into political science courses.
\end{abstract}

JEL Codes: A22, C22, C90, D21, L10

Keywords: classroom experiment, location choice

Lisa R. Anderson (corresponding author)

Professor of Economics

College of William and Mary

Williamsburg, VA 23185

lrande@wm.edu

Beth A. Freeborn

Assistant Professor of Economics

College of William and Mary

Williamsburg, VA 23185

bafree@wm.edu

Jessica Holmes

Assistant Professor of Economics

Middlebury College

Middlebury, VT 05753

jholmes@middlebury.edu
Mark Jeffreys

Associate Professor of Integrated Studies

Utah Valley State College

Orem, UT 84058-5999

jeffrema@uvsc.edu

Dan Lass

Professor of Resource Economics

University of Massachusetts

Amherst, MA 01003

dan.lass@resecon@umass.edu

Jack Soper

Professor of Economics and Finance

John Carroll University

University Heights, OH 44118

jsoper@jcu.edu 


\section{Location, Location, Location! A Classroom Demonstration of the Hotelling Model}

Imagine my surprise when I left the comedy club one day and walked to the end of the block and there on one corner was a Starbucks and across the street from that Starbucks, in the exact same building as that Starbucks, there was a Starbucks. I looked back and forth thinking the sun was playing tricks with my eyes. But there was a Starbucks across from a Starbucks. And that, my friends, is the End of the Universe...

\section{-Comedian Lewis Black}

Last July, Chicagoist mentioned that we're getting a Hershey's store in town...Funny thing though. The location of the Hershey's store is pretty much right across the street from the Ghirardelli shop. We know that Ghirardelli is more upscale that Hershey's, that it tries to be more like a soda fountain with sundaes and shakes and huge cookies and Hershey's is more...well...Hershey's...but can that little water tower square on North Michigan avenue really support TWO chocolate shops?

- "Hershey's store right next to Ghirardelli Shop” posted on Chicagoist.com,3/22/05

\section{Introduction}

The theory of spatial location introduced by Hotelling (1929) can be used to explore a number of interesting economic questions. ${ }^{1}$ For example, why might there be two chocolate shops on the same block or why do television networks schedule similar shows at the same time? However, many instructors miss the opportunity to bring location theory into the classroom because the theory of spatial competition can often seem very technical and abstract.

This paper outlines a classroom experiment that complements the theoretical discussion of Hotelling's spatial competition model. This experiment can be used to discuss competitive clustering in introductory classes, resolutions to the Bertrand paradox in intermediate classes, and product positioning in more advanced classes. ${ }^{2}$ The basic set up builds on the exercise introduced in Eber (2002) with several important modifications. First, the Eber (2002) exercise requires that the classroom be physically rearranged prior to class with the desks in the room serving as the different vendor locations. Our experiment requires only the photocopying of instructions prior to class. Second, in Eber (2002), some students make decisions as buyers. 
Given the simplicity of the buyer decision, we simulate it in our exercise and all students act as firms. Lastly and perhaps most importantly, we present extensions of the basic setup for use in intermediate and advanced classes.

The experiment places the student in the role of a street vendor who must choose his or her optimal location in a "linear city." Like Hotelling's vendors, each student chooses a location for his or her cart, taking into account the possible locations of competitors and the transportation costs and distribution of potential customers. In the simple two firm scenario with fixed prices, students witness first-hand the (sometimes counterintuitive) Nash equilibrium in which both firms choose the same location. Students also observe how quickly the Bertrand paradox is resolved by adding the element of product differentiation. After playing a two-stage game involving both location and price decisions, students gain a deeper understanding of the intense price competition often observed between clustered firms. Additionally, the instructor can allow communication between firms in order to examine tendencies toward a cooperative outcome. For more advanced courses, the exercise has been extended to include three firms. ${ }^{3}$

This classroom experiment can be easily implemented in any size class, in any type of classroom, with very little preparation. It is well-suited for courses in microeconomics, industrial organization, game theory, experimental economics, public choice, and urban economics. It also can be incorporated into management, geography and political science courses. ${ }^{4}$ After a bit of preamble detailing a fictional city licensing system, a vendors association, and pretzels that "fall off the back of a truck" each morning, the instructions for each exercise only ask players to make one or two decisions per round: pick a location, set a price, or pick a location and set a price. Because the imaginary customers accrue to each vendor according to a pre-established arithmetic, no one needs to play the part of the customers. Decisions are recorded on handouts, and the 
results can be quickly hand-calculated. Instructors can also choose the parts of the experiment that are most relevant to the material covered in their course using Table 1 as a guide.

This format makes the exercise extremely user-friendly for an instructor. The class can be of any size in any type of room. All students play the same role, and no one needs to relocate during the game. The only materials are the instructions/record sheets which are included at the end of the paper and are easily reproduced and photocopied. Each part of the experiment can be played quickly, for several rounds without taking up much class time. The "moral" of the story is vivid and immediate and leads naturally into a discussion and lecture presenting the general principles of Hotelling location models.

Students may be assigned more complicated versions as homework, or the instructor may add a more complex exercise using web-based software, such as Veconlab at the University of Virginia, for students to $\log$ into after class. ${ }^{5}$ Alternatively, students can be assigned the task of creating their own more complex versions of the game, as individuals or in teams, and those versions might be submitted as homework or given trial runs in the classroom. In the latter case, students not only learn about Hotelling models but also learn about experimental game design. Finally, Appendix A provides some questions that can be assigned for homework or used to stimulate classroom discussion.

\section{Experimental Setup}

In this section, we describe the basic experimental procedures. Prior to class, the instructor should photocopy red and blue sets of the instructions/student worksheets (found in Appendix B). ${ }^{6}$ For instructors who intend to extend the analysis to three vendors, green worksheets will also be required. When handing out instructions, alternate between Red and Blue 
(and Green) in the same order so that the number of students assigned a particular color is roughly equal across colors being used.

We begin the experiment by describing a very basic Hotelling (1929) model where consumers are uniformly distributed along a nine block region of a city street and vendors sell pretzels from a mobile cart. Heavy regulations require that street vendors obtain licenses from City Hall each morning. The color of the student worksheet implies a type of vendor and each student will be paired with another student of a different color. For example, in a class of 24 students with two vendor types, there will be 12 red-blue vendor pairings and with three vendors types there will be 8 red-blue-green vendor groups. Within a pairing/group, students act as rival vendors along their nine block region. During each round, student-vendors make decisions about cart location and/or price on their worksheet and then reveal their choice(s) to their rival(s). Students then calculate quantity demanded and earnings based on the choices of all vendors in their rival group. Each round should take one or two minutes.

Table 1 describes all of the variations of the exercise and can be used as a guide in choosing which parts of the exercise are most relevant for your class. Note that this experiment is an example of a discrete Hotelling model and as such requires some generalities regarding the specific theoretical equilibria when discussing in advanced courses. Usually, instructors derive Nash Equilibria in spatial competition models using a continuum of consumers or locations. Although this exercise does not lead to the theoretical equilibria derived from a continuous model, the experiment provides a good starting point to location theory in an Industrial Organization course.

For all parts of the experiment, consumer demand is simple. All consumers place a value on consuming pretzels and face two costs, the price of the pretzel and the transportation (or 
disutility) cost of traveling to reach a vendor. Thus, the net value to consumers is the value of a pretzel minus the vendor price minus the transportation cost. The price of the pretzel is either determined by the City or the vendors. Transportation costs, which are only relevant when vendors choose price, are constant and equal to $\$ 0.10$ for each block traveled. There are 10 consumers per block and each purchases one pretzel per day from the vendor that gives her the highest net value. ${ }^{7}$ If both vendors are located in the same block, each vendor receives 5 consumers from that block. The result of this demand setup is that for identical prices, consumers buy from the closest vendor.

Another element of the model is constant throughout the exercise. Vendors offer homogeneous products and face zero costs; cases of pretzels magically arrive at their carts each morning. If desired, instructors can enforce a constant marginal cost (identical for all vendors) without loss of generality.

\section{$\underline{\text { Part 1: Location Choice }}$}

In Part 1.1 of the experiment, the City provides licenses to two street vendors per nine block region and limits price to $\$ 1$ per pretzel. To form rival pairs, ask students to pair with another student of a different vendor color. Although City Hall sets price, vendors may choose their block location. As an example within one rival pair, student-vendors (i.e., Vendor Red and Vendor Blue) may initially select the two positions, red and blue, shown below:

\begin{tabular}{|l|l|l|l|l|l|l|l|l|}
\hline Block 1 & Block 2 & Block 3 & Block 4 & Block 5 & Block 6 & Block 7 & Block 8 & Block 9 \\
red
\end{tabular}


After a round or two of experimentation, Vendor Red will realize that by locating just to the left of Vendor Blue (in block 6), she can have all customers to her left. Vendor Red would capture a majority of the market. Vendor Blue would then move to a position just to the left of red, and so on until both vendors arrive at the center. With both vendors located at the center block, they will share equally the consumers, (i.e., each vendor will serve 45 consumers). They have no incentives to relocate as a location change would result in loss of market share. This quick exercise allows students to experience first-hand the Nash position in location strategy; once both vendors arrive at this equilibrium location, neither will want to move. This simple Hotelling experiment can be used to explain why we observe a number of competing stores locating at the same point along city streets, such as clusters of gas stations or competing fast food restaurants at the same intersections. Instructors may supplement the discussion by introducing results from research experiments such as the Hotelling duopoly experiments in Brown-Kruse, Cronshaw and Schenk (1993).

For more advanced students, Parts 1.2-1.3 allow the instructor to extend the experiment to three vendors and introduce the notion of sequential moves. Naturally not all class sizes are divisible by three, so once every rival group has the correct number of students, there may be some students without a rival group. These students should either be paired with another student to act as a single vendor or act as silent observers to nearby groups and return to the exercise in

\section{Part 2.}

In Part 1.2, the City allows three vendors to operate within a nine block region with no other changes in the rules. Although Hotelling originally projected that the centrist tendency observed with two vendors would persist with more vendors, subsequent work by others proved that firm clustering breaks down with more than two agents. With three firms there is no pure- 
strategy Nash equilibrium with simultaneous entry (Eaton and Lipsey, 1975). Thus, with no guidance from theory, we might expect students to relocate from round to round in an effort to "leapfrog" other players.

Part 1.3 of the exercise explores sequential entry with three firms. Theory from a continuous game suggests that the first two vendor entrants will differentiate themselves by separately occupying block 3 and block 7 and the third vendor will locate on block $5 .{ }^{8}$ However, due to the discrete nature of this exercise, there are actually multiple equilibria. For example, when the first two vendors locate at block 3 and 7, the third vendor is indifferent between locating at blocks $2,4,5,6$, and 8 ; these locations all earn the third entrant $\$ 20(=20$ pretzels sold at \$1 per pretzel) and none of the vendors wish to relocate. During this exercise, Vendor Red chooses her location first, and then reveals her choice to the other vendors; Vendor Blue then considers Vendor Red's position and chooses (and reveals) his location; Green is the last vendor to choose and reveal.

\section{$\underline{\text { Part 2: Price Choice }}$}

In Part 2 of the experiment, the City dramatically changes its policy; only two vendors are permitted to operate in each region, each vendor is assigned a location and each vendor is free to set price (up to a maximum of $\$ 5$ ). ${ }^{9}$ Further, price discrimination is not allowed. We continue to assume that pretzels magically appear (without cost) each morning at the vendors' carts. In Part 2.1, vendors are assigned locations at the same spot (in the center). In Part 2.2, vendors are assigned locations at the extremes (one vendor in block 1 and one vendor in block 9). Under both treatments, vendors know the location of their rival when choosing price. Theory predicts that prices will be equal to zero (marginal cost) when vendors are located in the same 
block because vendors are identical in the eyes of consumers. Theory predicts prices are higher when vendors are located at the extremes because consumer transportation costs essentially create product differentiation. In practice you are likely to see prices above marginal cost under both treatments. Even when students are located in the same block and thus face intense competition from their rival, they recognize that they will earn nothing by pricing at zero. ${ }^{10}$ Prices will be higher, however, under separation than when firms are located in the same block.

\section{Part 3: Location and Price Choice}

In Part 3.1 of the experiment, the City imposes fewer constraints on the two vendors; they are free to choose both location and price (up to a maximum of \$5). Location is chosen simultaneously and then announced. In a second stage, vendors simultaneously choose price.

Comparative static analysis of the problem shows that both vendors will increase profits (given price) by moving toward each other. However, if this location strategy (one of minimum differentiation) continued and the vendors also compete in price, then price would be driven to zero. This is the classic Bertrand Paradox. Suppose both vendors locate at the same point. Now, with consumers facing transportation costs, Vendor Red could earn positive profit by moving away from Vendor Blue and vice versa. Vendor Red, for example, could charge a price that was just less than the additional transportation costs the consumers would face in passing Vendor Red to get to Vendor Blue. Of course, Vendor Blue would realize the same possibility. With continuous time and price, you might envision both vendors playing leapfrog down the blocks, and constantly changing prices depending on where their competitor is located. ${ }^{11}$ Part $\mathbf{3 . 2}$ repeats the exercise but allows non-binding communication between vendors. This scenario is designed to explore collusive behavior. Students can compare the outcomes in Parts 3.1 and 3.2 
to see whether a cooperative outcome is achieved with communication. Any outcome in which all of the consumers pay $\$ 5$ per pretzel maximizes combined earnings for the pair.

\section{Sample Results and Related Discussion}

This section discusses results from a 400-level industrial organization class with 9 students, displayed in Table 2. The experiment and class discussion of results took place in a 75minute period. We provide these sample results as an example of how students might behave in the experiment and as a guide for class discussion. Of course, you should tailor your class discussion to the behavior you observe with your students. You also may find it useful to share the sample results in Table 2 with your class.

\section{$\underline{\text { Part } 1.1}$}

Notice in Table 2 that not all students located in the center of the linear street in the first couple of rounds in Part 1.1. By the third round of Part 1.1 (i.e., Day 3), all but one student

located in Block 5, as predicted by theory. ${ }^{12}$ If you observe this pattern in your class, ask students to explain why they gravitated to Block 5. In every classroom trial of this experiment students have explained that the center block is the only one that prevents a vendor from being exploited by the competitor. This leads nicely into a discussion of Nash equilibrium. For any other pair of location choices that a student proposes as an equilibrium, ask the class to think about whether either vendor will regret her choice ex post. At any pair of locations other than the 5, 5 outcome at least one vendor could have made a better choice given the location of the other vendor. 
To tie the example back into real world experiences, you can also ask students to think of examples of firm clustering in their hometowns or cities that they have visited. Anecdotal evidence suggests that in the 1950's Burger King Executives monitored McDonalds' new retail locations and then moved in down the block. In the 1970's, Pizza Hut followed the same location strategy. You can also have students brainstorm for explanations of firm clustering other than the predictions from location theory. For example, firms may locate near competitors to monitor rivals, to reduce the cost of hiring qualified workers, to benefit from technology diffusion or to free ride on advertising by rivals.

\section{$\underline{\text { Part } 1.2 \text { - Part } 1.3}$}

Part 1.2 introduces simultaneous entry by a third competitor. In this case there is no Nash equilibrium in pure strategies. Working through the same thought process used in Part 1.1 will help students realize this. As Table 2 suggests, most students vacated block 5 when the third competitor was added. Individual results show students moving locations each day, searching for higher payoffs. Because there is no pure strategy Nash Equilibrium, this part of the exercise might confuse some students. However, combined with Part 1.3, the simultaneous three vendor case demonstrates how sequential entry can solve coordination problems in location games.

Part 1.3 asks three rival vendors to choose locations in sequence. Begin the discussion by asking students how their decision making process changed from Part 1.2 to 1.3. During this discussion, students are likely to mention the early mover advantage in the sequential version of the game. In theory, first and second movers make between $\$ 30$ and $\$ 40$ (locating in Block 3 and Block 7), depending on the location of the third entrant, while the third entrant makes \$20 (locating in Block 2, 4, 5, 6 or 8). Table 2 shows that class results gravitated towards this 
outcome and behavior was consistent with theory by Day 3. As in Part 1.2, very few students located in the four outer blocks (1, 2, 8 and 9).

Students might also mention that the sequential location process helped them to coordinate locations relative to the simultaneous choice. This can lead to a discussion about why the city planner might care about where firms locate. For example, the city planner might want to separate retail and residential areas, which would suggest that vendors locate in the same block. Alternatively, the city planner might want to space the carts out along the street to minimize overcrowding of city sidewalks, streets, or consumer transportation costs. Transportation costs are minimized in the two vendor case when they locate in block 3 and block 7 , and in the three vendor case when they locate in block 2, block 5 and block 8 .

\section{$\underline{\text { Part } 2}$}

Parts 2.1 and 2.2 return to the two vendor simultaneous choice problem. Vendors are assigned to locations and asked to choose prices. These scenarios are slightly more complicated since vendors have a richer set of choices. When pairs of vendors are assigned to the same location (Block 5) theory predicts that price will be driven to $\$ 0$. At the opposite ends of the spectrum (Block 1 and Block 9), theory predicts that prices will be higher than marginal cost. With a continuous model each vendor charges a price equal to marginal cost plus transportation cost. Unfortunately, the discrete case does not have a pure strategy Nash Equilibrium in prices, but it is easy to show that marginal cost pricing is no longer an equilibrium.

Looking at the sample results in Table 2, we observe that for Part 2.1, actual prices were well above the prediction (at $\$ 1.21$ ) on Day 1 and fell to $\$ 0.37$ on Day 2. At this point, the instructor can discuss the Bertrand paradox when goods are identical: vendors located in the 
same block are identical and so price is driven down to marginal cost. In Part 2.2 where vendors were assigned to disparate locations, prices began at $\$ 1.10$ on Day 1 and increased to $\$ 1.28$ on Day 2. Thus, adding differentiation in the form of different locations, resolves the Bertrand paradox of Part 2.1 and price is greater than marginal cost. While many instructors provide theoretical discussions of Bertrand and lists of possible resolutions to the paradox, this exercise provides students the opportunity to actively engage in the process.

\section{$\underline{\text { Part } 3}$}

In Part 3.1, students simultaneously choose location, reveal locations, and then simultaneously choose price. Because there is no equilibrium in either the continuous model or the discrete model, you might observe a great deal of instability in students' choices. Table 2 shows that prices were lower here than when students could not choose location. Despite the fact that there is no Nash equilibrium in the location-price choice model, there was a clear tendency for students to locate in the center block. Ask students to articulate the tradeoff between gaining market share and engaging in a price war in this location-price model. Specifically, you can discuss the direct effect (for a given set of prices, firms locate closer to their competitor in order to increase demand) and then the strategic effect (the closer a firm is to its rival, the more intense price competition will be).

In Part 3.2, students were allowed to communicate with their rival prior to making location and price choice. As noted above, combined earnings are maximized when all consumers pay $\$ 5$ per pretzel. Collusive outcomes that split consumers equally between the two vendors are likely to be discussed. Of course, the communication is "cheap talk" in the sense that no agreements are binding, so you may observe big differences in earnings within a pair if one 
vendor cheats on their agreement. When students were allowed to talk, many vendor-pairs successfully colluded to set prices near $\$ 5.00$. However, because each day is considered a singleshot game, some students cheated on the collusive price which led to an average price of $\$ 4.63$ in Day 1 and then $\$ 4.13$ in Day 2. With communication allowed, most pairs located in the center block.

There are many discussion points that are appropriate regardless of the choices students make in the experiment. In each scenario, ask students what they think economic theory predicts about behavior and compare the classroom results to the theoretical predictions. When theory and behavior are different, ask students to explain why. ${ }^{13}$ You can also have students design and predict outcomes for additional classroom scenarios. For example, what if customers were not evenly distributed across the blocks $?^{14}$ What if the marginal costs of the rivals differed? Finally, ask students to consider other applications of Hotelling. In addition to firm clustering, Hotelling's classic model has been used to explain the tendency for products to be similar and for political parties to move to the ideological center; moderate candidates tend to win elections, automakers tend to introduce comparable products each year and television networks schedule similar programs in the same time slot. For other discussion questions, see Appendix A.

\section{Concluding Remarks}

This classroom experiment provides students the opportunity to actively think about location and price choice. However location theory can be applied to many different problems, and as such, some parts of this exercise can be implemented in Microeconomics, Industrial Organization, Game Theory, Urban Economics, Public Choice, Experimental Economics, Management, Geography and Political Science courses. Using Table 1 as a guide, instructors can 
choose the scenarios that are most relevant to their specific course. Implementation is easy; preparation outside of class is limited to photocopying, students can easily form groups, and no rearrangement of the classroom is necessary. The exercises can be done quickly, and for several rounds. Lastly, and most importantly, students quickly gain a deeper understanding of several complex, and often counterintuitive spatial competition models, and the experiment easily generates lively classroom discussion. 
Table 1. Variations of the Location Choice Game

\begin{tabular}{ccccccc}
\hline Part & $\begin{array}{c}\text { Number } \\
\text { of } \\
\text { Vendors }\end{array}$ & $\begin{array}{c}\text { Vendors } \\
\text { Choice } \\
\text { Variable }\end{array}$ & $\begin{array}{c}\text { Simultaneous } \\
\text { or Sequential }\end{array}$ & $\begin{array}{c}\text { Transportation } \\
\text { Costs }\end{array}$ & $\begin{array}{c}\text { Miscellaneous } \\
\text { Details }\end{array}$ & $\begin{array}{c}\text { Class } \\
\text { Level }\end{array}$ \\
\hline 1.1 & 2 & Location & Simultaneous & None & & Beginner \\
\hline 1.2 & 3 & Location & Simultaneous & None & Beginner \\
\hline 1.3 & 3 & Location & Sequential & None & Assigned Same & Intermediate \\
\hline 2.1 & 2 & Price & Simultaneous & Linear & $\begin{array}{c}\text { Location } \\
\text { (Block 5) }\end{array}$ & \\
\hline 2.2 & 2 & Price & Simultaneous & Linear & $\begin{array}{c}\text { Assigned Opposite } \\
\text { Locations } \\
\text { (Blocks 1 and 9) }\end{array}$ & Intermediate \\
\hline 3.1 & 2 & $\begin{array}{c}\text { Location } \\
\text { then Price }\end{array}$ & Simultaneous & Linear & Intermediate \\
\hline 3.2 & 2 & $\begin{array}{c}\text { Location } \\
\text { then Price }\end{array}$ & Simultaneous & Linear & $\begin{array}{c}\text { Communication } \\
\text { Allowed }\end{array}$ & Intermediate \\
\hline
\end{tabular}


Table 2. Class Results from Location Choice Game

Number of Students Located in Each Block**

\begin{tabular}{|c|c|c|c|c|c|c|c|c|c|c|c|c|c|}
\hline Part & Day & $\begin{array}{c}\text { Number } \\
\text { of } \\
\text { Vendors }\end{array}$ & $\begin{array}{c}\text { Vendors } \\
\text { Choice } \\
\text { Variable* }\end{array}$ & $\begin{array}{c}\text { Average } \\
\text { Price }\end{array}$ & 1 & 2 & 3 & 4 & 5 & 6 & 7 & 8 & 9 \\
\hline 1.1 & 1 & 2 & $\mathrm{~L}$ & $\mathrm{n} / \mathrm{a}$ & & & 2 & 1 & 3 & & 1 & 1 & \\
\hline 1.1 & 2 & 2 & $\mathrm{~L}$ & $\mathrm{n} / \mathrm{a}$ & 1 & & & 1 & 5 & 1 & & & \\
\hline 1.1 & 3 & 2 & $\mathrm{~L}$ & $\mathrm{n} / \mathrm{a}$ & & & & 1 & 7 & & & & \\
\hline 1.2 & 1 & 3 & $\mathrm{~L}$ & $\mathrm{n} / \mathrm{a}$ & & & & 3 & 1 & & 5 & & \\
\hline 1.2 & 2 & 3 & $\mathrm{~L}$ & $\mathrm{n} / \mathrm{a}$ & & & & 2 & 4 & 2 & 1 & & \\
\hline 1.2 & 3 & 3 & $\mathrm{~L}$ & $\mathrm{n} / \mathrm{a}$ & & & & 5 & 1 & 1 & & & 2 \\
\hline 1.3 & 1 & 3 & $\mathrm{~L}$ & $\mathrm{n} / \mathrm{a}$ & & & 1 & 3 & 2 & 1 & 2 & & \\
\hline 1.3 & 2 & 3 & $\mathrm{~L}$ & $\mathrm{n} / \mathrm{a}$ & & & 1 & 1 & 3 & 2 & 1 & & 1 \\
\hline 1.3 & 3 & 3 & $\mathrm{~L}$ & $\mathrm{n} / \mathrm{a}$ & & & 3 & 1 & & 2 & 3 & & \\
\hline 2.1 & 1 & 2 & $\mathrm{P}$ & 1.21 & & & & & 8 & & & & \\
\hline 2.1 & 2 & 2 & $\mathrm{P}$ & 0.37 & & & & & 8 & & & & \\
\hline 2.2 & 1 & 2 & $\mathrm{P}$ & 1.10 & 4 & & & & & & & & 4 \\
\hline 2.2 & 2 & 2 & $\mathrm{P}$ & 1.28 & 4 & & & & & & & & 4 \\
\hline 3.1 & 1 & 2 & $\mathrm{~L} / \mathrm{P}$ & 0.61 & & & 1 & & 5 & 1 & 1 & & \\
\hline 3.1 & 2 & 2 & $\mathrm{~L} / \mathrm{P}$ & 0.60 & & & & 3 & 4 & 1 & & & \\
\hline 3.2 & 1 & 2 & $\mathrm{~L} / \mathrm{P}$ & 4.63 & & & & & 8 & & & & \\
\hline 3.2 & 2 & 2 & $\mathrm{~L} / \mathrm{P}$ & 4.13 & 1 & 1 & & & 5 & & & & 1 \\
\hline
\end{tabular}

*L indicates location choice, $\mathrm{P}$ indicates price choice and $\mathrm{L} / \mathrm{P}$ indicates location and price choice.

** In Parts 1.2 and 1.3 there are a total of 9 vendors because there were 9 students in class. In all other parts, the ninth student paired up with another student to act as a single vendor, for a total of 8 vendors. 


\section{Endnotes}

${ }^{1}$ For example, Hotelling's model is discussed in Frank's Microeconomics and Behavior (2006), Nicholson's Microeconomic Theory: Basic Principles and Extensions (2005), Cabral's Introduction to Industrial Organization (2000), Shy's Industrial Organization: Theory and Applications (1996), and Tirole's The Theory of Industrial Organization (1988).

2 Several controlled studies report significantly higher performance on exams by students who participate in classroom experiments relative to those who do not. See, for example, Frank (1997), Gremmen and Potters (1997), Emerson and Taylor (2004) and Durham, McKinnon and Schulman (2007) for a discussion of this issue.

${ }^{3}$ The exercise could also be adapted to include four firms and quadratic (rather than linear) transportation costs.

${ }^{4}$ Location theory is often used to explain the clustering of political candidates and parties at the center of the political spectrum. For an example using location theory in a classroom game, see Wilson (2005).

${ }_{5}^{5}$ Any two-person simultaneous choice problem can be conducted using the " $2 \times 2$ matrix game" option at veconlab.econ.virginia.edu/admin.htm.

${ }^{6}$ Alternatively, you can purchase a pack of colored star stickers, like the ones frequently used by elementary school teachers, to assign roles in the experiment. Place one colored star on the front page of each instructions packet to assign roles and facilitate the matching process.

${ }^{7}$ A variation of this exercise is presented as an end of chapter problem (chapter 6, problem 5) in Dixit and Skeath's (2004) undergraduate game theory text.

${ }^{8}$ Prescott and Visscher (1977) describe a unique pure strategy Nash equilibrium in the case where the linear market is normalized to the unit interval, the first vendor locates at $1 / 4$, the second locates at $3 / 4$ and the third locates at $1 / 2$.

${ }^{9}$ If the instructor includes the three vendor exercise of Parts 1.2 and 1.3, then the instructor should ask students to return to the original pairings to complete Parts $\mathbf{2}$ and $\mathbf{3}$.

${ }^{10}$ Ortmann (2003) presents results from several classroom sessions of a Bertrand pricing experiment and reports that students tend to price closer to marginal cost than to the maximum price allowed. However, very few students price at the marginal cost of zero.

${ }^{11}$ D'Aspremont, et. al. (1979) show that when both location and price are choices, a Nash Equilibrium does not exist with linear transportation costs.

${ }^{12}$ When designing this classroom experiment we were initially concerned that the simplicity of the decision in Part 1.1 would render the solution transparent rather than counterintuitive, thus making the learning experience less memorable. However, when we pilot tested it on a roomful of academic economists, the participants did not move directly to the equilibrium locations--or they did so, but then went on to experiment by trial and error for a few rounds, moving their locations away from equilibrium to see if any competitive advantage could be gained. Deviations from theory observed in the classroom provide an opportunity to connect the experiment to the real world. For example, this basic model does not capture every dimension of an actual location decision. An individual may choose to locate a business close to home, public transportation, etc. Making decisions based on these other considerations may open the door for one's rival to earn greater profits.

${ }^{13}$ The level and focus of the course will determine how much the instructor wants to discuss theoretical predictions. Because this exercise uses a discrete version of Hotelling, the actual equilibrium predictions are quite complicated to derive in a classroom. However, instructors may use the general results from their classroom experiment as a benchmark when discussing the theoretical predictions of equilibrium in the continuous Hotelling Model.

${ }^{14}$ See Eber (2002). 


\section{References}

Brown-Kruse, J. Cronshaw, M and Schenk, D. 1993. "Theeory and Experiments on Spatial Competition." Economic Inquiry. 31(1): 139-165.

Cabral, Luis M. B. 2000. Introduction to Industrial Organization, Cambridge, Massachusetts: The MIT Press.

D’Aspremont, C., J. Jaskold Gabzewicz, and J. F. Thisse. 1979. “On Hotelling's 'Stability in Competition." Econometrica. 47: 1145-1150.

Dixit, Avinash and Susan Skeath. 2004. Games of Strategy, New York: W. W. Norton \& Company.

Durham, Yvonne, Thomas McKinnon, and Craig Schulman. 2007. "Classroom Experiments: Not Just Fun and Games," Economic Inquiry. 45(1): 162-178.

Eaton, B.C. and R.G. Lipsey.1975. "The Principle of Minimum Differentiation Reconsidered: Some New Developments in the Theory of Spatial Competition." Review of Economic Studies. 42(1): 27-49.

Eber, N. 2002. "Hotelling in the Classroom” Classroom Expernomics. Volume 11.

Emerson, Tisha L. N. and Beck A. Taylor. 2004. "Comparing Student Achievement across Experimental and Lecture-Oriented Sections of a Principles of Microeconomics Course," Southern Economic Journal. 70(3): 672-693.

Frank, Bjorn. 1997. "The Impact of Classroom Experiments on the Learning of Economics: An Empirical Investigation," Economic Inquiry. 35(4): 763-69.

Frank, Robert H. 2006. Microeconomics and Behavior $\left(5^{\text {th }}\right)$, New York: McGraw-Hill Irwin.

Gremmen, H. and J. Potters. 1997. "Assessing the Efficacy of Gaming in Economic Education." Journal of Economic Education. 28: 323-43.

Hotelling, H. 1929. "Stability in Competition." Economic Journal. 39(153): 41-57.

Nicholson,Walter. 2005. Microeconomic Theory: Basic Principles and Extensions $\left(8^{\text {th }}\right)$, Fort Worth: Dryden Press.

Ortmann, Andreas. 2003. "Bertrand Price Undercutting: A Brief Classroom Demonstration." Journal of Economic Education: 34(1): 21-26.

Prescott, E.C. and Visscher, M. 1977. "Sequential Locations among Firms with Foresight." Bell Journal of Economics. 8(2): 378-393. 
Shy, O. 1996. Industrial Organization: Theory and Applications. Cambridge, Massachusetts: The MIT Press.

Tirole, Jean. 1988. The Theory of Industrial Organization. Cambridge, Massachusetts: The MIT Press.

Wilson, Rick. 2005. "Classroom Games: Candidate Convergence" The Southern Economic Journal.71(4): 913-922. 


\section{Appendix A. Discussion Questions}

\section{Part 1}

1. Why might the City regulate the number of licenses? Who are the winners and who are the losers of this regulation?

2. How is location choice related to the concept of product differentiation?

3. After a few rounds, most vendors gravitate to Block 5. Why? Is there another location pair choice that would have made both vendors better off?

4. How can the results of the exercise explain why we often observe firm clustering? What firm clustering do you observe in this town?

5. Can you think of other reasons why firms might choose to cluster in one location?

6. Does product type have an impact on the reason that firms may choose to cluster? For example, is there any difference in clustering of firms that sell infrequently purchased, high priced "shopping goods" or frequently purchased, low priced "convenience goods"?

7. In this example, is the clustering of firms socially optimal? If not, what would the socially optimal outcome look like?

8. How does the introduction of a third vendor alter the outcome?

9. With sequential entry, is there a first mover advantage?

10. How does sequential entry (as opposed to simultaneous entry) affect profits for a third vendor?

11. Why might the City regulate the location of vendors? Who are the winners and who are the losers of this regulation?

12. How can Hotelling's classic model be applied to television network scheduling? Political platforms of leading candidates? Other real world observations?

Part 2

1. How does rival location affect firm pricing decisions?

2. How is the Bertrand Paradox resolved here?

3. If the City is most concerned about maximizing consumer surplus, what regulations would be enacted?

4. If the City is most concerned with maximizing producer surplus, what regulations would be enacted?

Part 3

1. With choice over both location and price, what tradeoff do vendors face?

2. Do vendors have incentives to see transportation improved in the City (such that transportation costs fall for some or all consumers)?

3. How did communication alter the outcome?

4. Was this "cheap talk"? In the real world, how might collusive agreements be enforced?

Extensions to consider

1. How would the experiment change if consumers were not evenly distributed across the blocks?

2. What if the vendors' marginal costs differed?

3. What if vendors controlled more than one cart?

4. What if the City regulated price and location, but product quality differed?

5. What other factors (not addressed in this experiment) might enter the location decision of vendors? 


\section{Appendix B. Instructions for the Street Vendor Experiment}

You are a street vendor selling pretzels from a mobile cart. You operate in a city where street vendors are heavily regulated. Each morning you must visit City Hall and obtain a (free) license to set up your cart. The City has divided each street into nine block regions and only two street vendors are allowed to sell pretzels in each region.

Below is a picture of a sample region:

\begin{tabular}{|l|l|l|l|l|l|l|l|r|}
\hline Block 1 & Block 2 & Block 3 & Block 4 & Block 5 & Block 6 & Block 7 & Block 8 & Block 9 \\
\hline
\end{tabular}

The city planner requires all vendors to sell the same pretzels and to charge $\$ 1$ each. Market research has revealed that there are 10 pretzel customers in each block per day and each customer buys one pretzel from the closest vendor. If customers are equally far from the two vendors, half will go to vendor A and half will go to vendor B. In addition, if vendor A and vendor B operate in the same block, they share all customers equally.

Historically, the City has assigned one vendor to Block 1 and the other to Block 9. Notice that with this location assignment, all of the customers in Blocks 1 through 4 buy a pretzel from the vendor in Block 1 and all of the customers in Blocks 6 through 9 buy a pretzel from the vendor in Block 9. The vendors split the 10 customers in Block 5. Hence, each vendor sells 45 pretzels and earns $\$ 45$ in revenue. (Assume that there are no production costs. The pretzels "fall off of a truck" each morning in front of your house.) 
Part 1.1 (n=2): Thanks to a very effective lobbying effort by the Association of Professional Street Vendors, the City has now agreed to let vendors choose their own cart locations within a particular region subject to the following rules. When you go to City Hall in the morning to obtain your license, you must indicate the location (block) where you will sell your pretzels. You will not be told where the other vendor in your region will locate and neither of you can change your location throughout the day. Pretzel prices are still restricted to $\$ 1$ each.

Procedures

1. Find your rival for this experiment. For convenience, find a partner with a different color paper from you.

2. Without any discussion, choose your cart location on the street by circling the block number on the picture below. Do not reveal your choice to your rival until you are instructed to do so.

\section{Circle your choice for Day 1}

\begin{tabular}{|l|l|l|l|l|l|l|l|l|}
\hline Block 1 & Block 2 & Block 3 & Block 4 & Block 5 & Block 6 & Block 7 & Block 8 & Block 9 \\
\hline
\end{tabular}

Your location

Your earnings for Day 1

Your rival's location

Your rival's earnings for Day 1

\section{Circle your choice for Day 2}

\begin{tabular}{|l|l|l|l|l|l|l|l|l|}
\hline Block 1 & Block 2 & Block 3 & Block 4 & Block 5 & Block 6 & Block 7 & Block 8 & Block 9 \\
\hline
\end{tabular}

Your location

Your earnings for Day 2

Your rival's location

Your rival's earnings for Day 2

\section{Circle your choice for Day 3}

\begin{tabular}{|l|l|l|l|l|l|l|l|l|}
\hline Block 1 & Block 2 & Block 3 & Block 4 & Block 5 & Block 6 & Block 7 & Block 8 & Block 9 \\
\hline
\end{tabular}

Your location

Your rival's location
Your earnings for Day 3

Your rival's earnings for Day 3 
Part 1.2 (n=3): The City now allows three vendors to operate in each region. When you go to City Hall in the morning to obtain your license, you must indicate the location (block) where you will sell your pretzels. You will not be told where the other two vendors in your region will locate and none of you can change your location throughout the day. Pretzel prices are still restricted to $\$ 1$ each. As in Part 1.1, if two (and now possibly three) vendors locate in the same block, they share the customers in that particular block equally. Specifically, if two vendors locate in the same block, they each get 5 customers from that block, and if all three vendors locate in the same block, they each get $31 / 3$ customers from that block.

Procedures

1. Find a third rival to join your region. Each region should include a Red, Blue and Green vendor.

2. Without any discussion, choose your cart location on the street by circling the block number on the picture below. Do not reveal your choice to your rivals until you are instructed to do

so.

\section{Circle your choice for Day 1}

\begin{tabular}{|l|l|l|l|l|l|l|l|l|}
\hline Block 1 & Block 2 & Block 3 & Block 4 & Block 5 & Block 6 & Block 7 & Block 8 & Block 9 \\
\hline
\end{tabular}

Your location

Your earnings for Day 1

Your rival's location

Your rival's earnings for Day 1

Your rival's location

Your rival's earnings for Day 1

Circle your choice for Day 2

\begin{tabular}{|l|l|l|l|l|l|l|l|l|}
\hline Block 1 & Block 2 & Block 3 & Block 4 & Block 5 & Block 6 & Block 7 & Block 8 & Block 9 \\
\hline
\end{tabular}

Your location

Your rival's location

Your rival's location
Your earnings for Day 2

Your rival's earnings for Day 2

Your rival's earnings for Day 2

\section{Circle your choice for Day 3}

\begin{tabular}{|l|l|l|l|l|l|l|l|l|}
\hline Block 1 & Block 2 & Block 3 & Block 4 & Block 5 & Block 6 & Block 7 & Block 8 & Block 9 \\
\hline
\end{tabular}

Your location

Your rival's location

Your rival's location
Your earnings for Day 3

Your rival's earnings for Day 3

Your rival's earnings for Day 3 
Part 1.3 ( $n=3$, sequential entry): City Hall has just introduced a new policy: location assignments will be allocated first-come, first served and will be publicized at the City Hall. Thus, locations are chosen sequentially and subsequent entrants are told the location choices of previous entrants. Once chosen, vendors cannot change their location during the day. Pretzel prices are still restricted to $\$ 1$ each.

Procedures

1. Each morning, without fail, the vendors arrive in the following order: Red, Blue, and Green.

2. Red should choose and reveal his or her cart location on the street by circling and then displaying the block number on his or her worksheet. After observing Red's location choice, Blue should choose and reveal his or her cart location by circling and then displaying the block number on his or her worksheet. Finally, after observing the location choices of the others, Green should choose and reveal his or her cart location by circling and then displaying the block number on his or her worksheet.

\section{Circle your choice for Day 1}

\begin{tabular}{|l|l|l|l|l|l|l|l|l|}
\hline Block 1 & Block 2 & Block 3 & Block 4 & Block 5 & Block 6 & Block 7 & Block 8 & Block 9 \\
\hline
\end{tabular}

Your location

Your rival's location

Your rival's location
Your earnings for Day 1

Your rival's earnings for Day 1

Your rival's earnings for Day 1

\section{Circle your choice for Day 2}

\begin{tabular}{|l|l|l|l|l|l|l|l|l|}
\hline Block 1 & Block 2 & Block 3 & Block 4 & Block 5 & Block 6 & Block 7 & Block 8 & Block 9 \\
\hline
\end{tabular}

Your location

Your rival's location

Your rival's location
Your earnings for Day 2

Your rival's earnings for Day 2

Your rival's earnings for Day 2

\section{Circle your choice for Day 3}

\begin{tabular}{|l|l|l|l|l|l|l|l|l|}
\hline Block 1 & Block 2 & Block 3 & Block 4 & Block 5 & Block 6 & Block 7 & Block 8 & Block 9 \\
\hline
\end{tabular}

Your location

Your rival's location

Your rival's location
Your earnings for Day 3

Your rival's earnings for Day 3

Your rival's earnings for Day 3 
Part 2.1 ( $n=2$, assigned location, price choice): The City has decided to limit the number of vendors to two and to regulate location. All vendor pairs will be assigned to Block 5. Vendors cannot change their location throughout the day. However, thanks to more lobbying effort by the Association of Professional Street Vendors, the City has agreed to let vendors choose their own pretzel prices, subject to the following rules: Prices cannot change throughout the day and must not exceed $\$ 5$. Customers now take price and location into consideration. Assume that there is a $\$ 0.10$ cost to consumers for every block they must travel to buy a pretzel. Customers calculate price plus transportation cost (total price) for both vendors and buy from the vendor with the lower total price. In the case of a tie, customers within a block split equally between the two vendors.

Procedures:

1. Pair up with your rival from Part 1.1.

2. Circle your assigned cart location on the street by circling Block 5 on the picture below.

3. Now, indicate your pretzel price in the space labeled "Your price for Day 1." Do not reveal your price to your rival until you are instructed to do so.

4. Once prices are chosen and revealed, use the spaces across the top and bottom of the choice blocks to record the total price to customers on a block-by-block basis. For example, following along the top row of the table, the total price for customers in Block 4 (and Block 6) will be your price plus $\$ 0.10$. The total price for customers in Block 3 (and Block 7) will be your price plus $\$ 0.20$ and so on. Given the other vendor's price and location, make the same calculations for the other vendor and record them along the bottom row of the table. Customers buy from the vendor with the lower total price.

\section{Circle your assignment for Day 1}

\begin{tabular}{|c|c|c|c|c|c|c|c|c|}
\hline & & & & & & & & \\
\hline Block 1 & Block 2 & Block 3 & Block 4 & Block 5 & Block 6 & Block 7 & Block 8 & Block 9 \\
\hline
\end{tabular}

$\uparrow$ Total price to customer for purchasing from the other vendor $\uparrow$

Your price for Day 1 (multiplied by) Your number of customers for Day 1

(equals) Your earnings for Day 1

Circle your assignment for Day 2

\begin{tabular}{|c|c|c|c|c|c|c|c|c|}
\hline & & & & & & & & \\
\hline Block 1 & Block 2 & Block 3 & Block 4 & Block 5 & Block 6 & Block 7 & Block 8 & Block 9 \\
\hline
\end{tabular}

Your price for Day 2 (multiplied by) Your number of customers for Day 2

(equals) Your earnings for Day 2 
Part 2.2 ( $n=2$, assigned location, price choice): The City continues to regulate location. Now Red will be assigned to Block 1 and Blue will be assigned to Block 9. If the pair includes Green, they are assigned to either Block 1 or Block 9 (whichever is not currently assigned). Vendors cannot change their location throughout the day. Again, the City has agreed to let vendors choose their own pretzel prices, subject to the following rules: Prices cannot change throughout the day and must not exceed \$5. Again, customers take price and location into consideration. Assume that there is a $\$ 0.10$ cost to consumers for every block they must travel to buy a pretzel. Customers calculate price plus transportation cost (total price) for both vendors and buy from the vendor with the lower total price. In the case of a tie, customers within a block split equally between the two vendors.

Procedures:

1. Pair up with your rival from Part 2.1.

2. Circle your assigned cart location on the street by circling either Block 1 or Block 9 on the picture below.

3. Now, indicate your pretzel price in the space labeled "Your price for Day 1." Do not reveal your price to your rival until you are instructed to do so.

4. Once prices are chosen and revealed, use the spaces across the top and bottom of the choice blocks to record the total price to customers on a block-by-block basis. For example, following along the top row of the table, if you are located in Block 1, the total price for customers in Block 2 will be your price plus $\$ 0.10$. The total price for customers in Block 3 will be your price plus $\$ 0.20$ and so on. Given the other vendor's price and location, make the same calculations for the other vendor and record them along the bottom row of the table. Customers buy from the vendor with the lower total price.

Circle your assignment for Day 1

\begin{tabular}{|c|c|c|c|c|c|c|c|c|}
\hline & & & & & & & & \\
\hline Block 1 & Block 2 & Block 3 & Block 4 & Block 5 & Block 6 & Block 7 & Block 8 & Block 9 \\
\hline
\end{tabular}

Your price for Day 1 (multiplied by) Your number of customers for Day 1 (equals) Your earnings for Day 1

\section{Circle your assignment for Day 2}

\begin{tabular}{|c|c|c|c|c|c|c|c|c|}
\hline & & & & & & & & \\
\hline Block 1 & Block 2 & Block 3 & Block 4 & Block 5 & Block 6 & Block 7 & Block 8 & Block 9 \\
\hline
\end{tabular}

Your price for Day 2 (multiplied by) Your number of customers for Day 2 (equals) Your earnings for Day 2 
Part 3.1 ( $n=2$, price choice): Thanks to intense lobbying effort by the Association of Professional Street Vendors, the City has now agreed to let vendors choose their own cart locations within a particular region and to choose their own pretzel prices, subject to the following rules. When you go to City Hall in the morning to obtain your license, you must indicate the location (block) where you will sell your pretzels. You will not be told where the other vendor in your region will locate and neither of you can change your location throughout the day. Once you and your rival arrive at your chosen locations, you must independently choose your own pretzel prices. Prices cannot change throughout the day and must not exceed $\$ 5$. Customers take price and location into consideration. Assume that there is a $\$ 0.10$ cost to consumers for every block they must travel to buy a pretzel. Customers calculate price plus transportation cost (total price) for both vendors and buy from the vendor with the lower total price. In the case of a tie, customers within a block split equally between the two vendors.

Procedures:

1. Pair up with your rival from Part 2.2.

2. Without any discussion, choose your cart location on the street by circling the block number on the picture below. Do not reveal your choice to your rival until you are instructed to do so. 3. Once you reveal your location choice, indicate your pretzel price in the space labeled "Your price for Day 1." Do not reveal your price to your rival until you are instructed to do so. 4. Once prices are chosen and revealed, use the spaces across the top and bottom of the choice blocks to record the total price to customers on a block-by-block basis, as you did in parts 2.1 and 2.2. Again, customers buy from the vendor with the lowest total price.

\section{Circle your choice for Day 1}

\begin{tabular}{|c|c|c|c|c|c|c|c|c|}
\hline & & & & & & & & \\
\hline Block 1 & Block 2 & Block 3 & Block 4 & Block 5 & Block 6 & Block 7 & Block 8 & Block 9 \\
\hline
\end{tabular}

Your rival's location

Your price for Day 1

Your number of customers for Day 1

Your earnings for Day 1

\section{Circle your choice for Day 2}

\begin{tabular}{|l|l|l|l|l|l|l|l|l|}
\hline & \multicolumn{1}{l}{ Total price to customers for purchasing from you $\downarrow$} \\
\hline Block 1 & Block 2 & Block 3 & Block 4 & Block 5 & Block 6 & Block 7 & Block 8 & Block 9 \\
\hline & & & & & & & & \\
\hline
\end{tabular}

$\uparrow$ Total price to customer for purchasing from the other vendor $\uparrow$

Your rival's location

Your number of customers for Day 2
Your price for Day 2 Your earnings for Day 2 
Part 3.2: You are selling pretzels under the same conditions as in Part 3.1, except that the administrators at City Hall are extremely busy. You and your rival have a few opportunities to talk during the licensing process.

Procedures:

1. Pair up with your rival from Part 1.1.

2. You have one minute to discuss your location choice with your rival. I will announce the end of discussion.

3. Choose your cart location on the street by circling the block number on the picture below. Do not reveal your choice to your rival until you are instructed to do so.

4. Reveal your location choice to your rival. You now have one minute to discuss your price choice with your rival. I will announce the end of discussion.

5. Next, indicate your pretzel price in the space labeled "Your price on Day 1" on your worksheet. Do not reveal your price to your rival until you are instructed to do so.

6. Once prices are chosen and revealed, use the spaces across the top and bottom of the choice blocks to record the total price to customers on a block-by-block basis, as you did in part 3.1. Again, customers buy from the vendor with the lower total price.

\section{Circle your choice for Day 1}

\begin{tabular}{|c|c|c|c|c|c|c|c|c|}
\hline & & & & & & & & \\
\hline Block 1 & Block 2 & Block 3 & Block 4 & Block 5 & Block 6 & Block 7 & Block 8 & Block 9 \\
\hline & & & & & & & & \\
\hline
\end{tabular}

$\uparrow$ Total price to customer for purchasing from the other vendor $\uparrow$

Your rival's location

Your price for Day 1

Your number of customers for Day 1

Your earnings for Day 1

\section{Circle your choice for Day 2}

\begin{tabular}{|l|l|l|l|l|l|l|l|l|}
\hline \\
\hline
\end{tabular}

$\uparrow$ Total price to customer for purchasing from the other vendor $\uparrow$

Your rival's location

Your number of customers for Day 2
Your price for Day 2

Your earnings for Day 2 